\title{
UNA OPORTUNA REVISIÓN DEL TRIENIO LIBERAL
}

\section{A TIMELY REASSESSMENT OF THE LIBERAL TRIENNIUM}

\author{
Francisco Carantoña Álvarez \\ Universidad de León
}

Recensión de / Review of: Pedro Rújula e Ivana Frasquet (coords.), El Trienio Liberal (1820-1823) Una mirada política, Comares, Granada, 2020, $601 \mathrm{pp}$.

Palabras clave: Liberalismo, monarquía, instituciones políticas, contrarrevolución, cultura, restauración.

Key Words: Liberalism, monarchy, political institutions, counterrevolution, Concert of Europe.

El libro coordinado por Pedro Rújula e Ivana Frasquet es la primera gran monografia sobre el Trienio que ve la luz al calor del bicentenario. Una obra necesaria, como puse de manifiesto en un reciente artículo ${ }^{1}$, extensa y que va más allá de lo que su subtítulo indica. Efectivamente, no faltan apartados sobre la sociedad y la cultura, solo que no incluya capítulos dedicados a la economía o a reformas como la supresión del régimen señorial o las desamortizaciones, de importante repercusión económica, explica que se presente como "una mirada politica". Los coordinadores argumentan, apoyándose en Julien Freund y Pierre Rosanvallon, que se trata "de pensar lo político en su conjunto, de comprenderlo también como el lugar de acción de toda la sociedad y no solo de los espacios destinados tradicionalmente a la política" ${ }^{2}$.

No es fácil comentar una publicación de estas características, en la que 25 autores redactan 23 capítulos, acertadamente agrupados en cinco grandes apartados: El Estado, La vida política, La sociedad, La cultura y El final. Será imposible hacerles justicia a todos, pero vaya por delante que comparten interés y calidad. Es cierto que algunos textos se acercan más a una síntesis realizada desde la revisión de la historiografia existente, algo en cualquier caso necesario con relación al Trienio, y en otros tiene más peso la utilización de fuentes directas, pero siempre se aportan nuevas perspectivas de análisis.

\footnotetext{
1 Francisco Carantoña Álvarez, "La historiografia sobre el Trienio Liberal: entre el estigma del fracaso y el enfoque militante", Pasado y Memoria. Revista de Historia Contemporánea, $\mathrm{n}^{\circ}$ 22, 2021, pp. 19-52.

2 Obra reseñada, p. XIII.
} 
Un libro que aborda tantos aspectos de forma monográfica tiene un interés indudable para los especialistas y para el público universitario, profesores y estudiantes, para los que se convertirá en obra indispensable de consulta, aunque puede resultar menos atractivo para el simple aficionado a la historia, que preferiria un planteamiento más cronológico, que le permitiese obtener con mayor facilidad una visión de conjunto. Cabe recomendar, en ese caso, la lectura previa de alguna de las dos sintesis sobre el Trienio recientemente aparecidas o reeditadas ${ }^{3}$, pero el primer capítulo, obra de Pedro Rújula -coautor precisamente de una de ellas-, tiene la virtud de seguir la trayectoria del rey, lo que le obliga necesariamente a realizar un recorrido por la evolución de los principales acontecimientos politicos.

Como señalaba anteriormente, el primer apartado se dedica al Estado. En él, Pedro Rújula y José Ramón Urquijo Goitia estudian, respectivamente, al rey y a los gobiernos. Define muy bien el primero el papel jugado por el monarca, "un elemento decisivo para la caída del régimen constitucional", no solo porque pudo bloquear o, al menos, dificultar el funcionamiento del sistema, "sino también por haber sido capaz de construir un relato convincente de lo que había sucedido en España y de conseguir que fuera asumido por las potencias extranjeras como una guía para la defensa de sus intereses en el tablero internacional y, por supuesto, también como justificación de la invasión de 1823. Este relato se componía de dos elementos principales: la debilidad del régimen y la cautividad del rey"4. A ello habría que sumarle su activa participación en las conspiraciones contrarrevolucionarias, incluso su dirección, como ha puesto de manifiesto Emilio La Parra 5 .

Urquijo realiza un exhaustivo repaso a los cambios ministeriales que, debido a su minuciosidad, agrava la sensación de inestabilidad política, una de las censuras que siempre recibió esta etapa histórica. $\mathrm{Si}$ ya son bastantes cinco ministerios para tres años y medio -el último realmente volátil, aunque fue el que tuvo que hacer frente a la invasión y acabó confinado en Cádiz-, la inclusión de ministros interinos y nombramientos fallidos empeora el panorama. Cabe indicar que, al especular sobre lo apropiado de la denominación de "gobierno de presidiarios" para el nombrado en la primavera de 1820, comete un error con Canga Argüelles que, como indica Carmen García Monerris, había sido temporalmente liberado en 1817, pero de nuevo encarcelado en Peñíscola en octubre de 1818, como consecuencia de la caída de su

3 Pedro Rújula y Manuel Chust, El Trienio liberal. Revolución e independencia (18201823), Catarata, Madrid, 2020. Alberto Gil Novales, El Trienio Liberal, PUZ, Zaragoza, 2020. Edición con estudio preliminar y bibliografia actualizada por Ramón Arnabat.

4 Obra reseñada, p. 35.

5 Emilio La Parra, Fernando VII. Un rey deseado y detestado, Tusquets, Barcelona, 2018. Emilio La Parra, Los Cien mil Hijos de San Luis. El ocaso del primer impulso liberal en España, Sintesis, Madrid, 2007. Emilio La Parra, "El rey y la contrarrevolución absolutista al final del Trienio Constitucional”, Bulletin d'Histoire Contemporaine de l'Espagne, n 37-42, 2004-2006, pp. 197-214. 
protector Garay, y salió directamente de la prisión al ministerio ${ }^{6}$. Según Alberto Gil Novales, Antonio Porcel también estaba detenido desde 1817 y fue liberado por el pueblo tras la revolución de $1820^{7}$. Habrian sido, por tanto, cuatro de siete los ministros presidiarios -cinco si se cuenta al posteriormente incorporado Cayetano Valdés-, algo, sin duda, inhabitual y que no permitiria considerar tan inapropiado el nombre con el que el gobierno pasó a la historia.

Con relación al poder legislativo, Encarna y Carmen García Monerris hacen un interesante análisis de la actividad parlamentaria, en el que destacan la activa participación política de la ciudadanía, que llegaba a las Cortes a través de ayuntamientos y diputaciones, pero también de representaciones individuales o colectivas y de la prensa periódica y la publicística, una de las características más relevantes del Trienio. Por su parte, Ignacio Durbán Martín entra en el terreno del derecho y la judicatura. Subraya la importancia de la legislación del Trienio, que califica de "excelsa", reflejada en "que muchas de las medidas adoptadas -o proyectadas- en el marco de esta corta y turbulenta etapa tuvieron su eco en sucesivas reformas operadas en diferentes momentos del siglo XIX"8. Frente a quienes inciden en un supuesto revanchismo liberal, explica que no hubo una represión política generalizada y que las depuraciones de jueces y magistrados fueron limitadas a quienes habían participado en la persecución de liberales y que, en cualquier caso, conservaron "honores, sueldos o jubilación". Se recuperó a los empleados de la justicia que habian sido represaliados, pero la permanencia de la mayoría de los jueces del antiguo régimen y una política de selección de los nuevos administradores de la justicia por parte del conservador Consejo de Estado bastante controvertida, permitieron que, "en la práctica, el número de jueces $\mathrm{y}$ magistrados partidarios del absolutismo fuese abundante". Este fue, ciertamente, un factor que contribuyó a dificultar la consolidación del nuevo sistema, algo que recuerda a lo sucedido en el siglo XX, en la transición a la democracia iniciada tras la muerte del general Franco, y que también tuvo efectos duraderos sobre el actual sistema constitucional.

Del ejército se ocupa Víctor Sánchez Martín, biógrafo de Rafael del Riego, que señala la presencia de los militares en las nuevas instituciones, elevada en el caso de las jefaturas políticas, pero no tanto en el parlamento. Según el estudio de Quintí Casal Bergés, lo fueron algo más del 16\% de los diputados elegidos en las elecciones de 1820 y

${ }^{6}$ Carmen García Monerris, "Discursos y prácticas de la tardoilustración: José Canga Argüelles (1771-1842)", en Encarna G. Monerris, Ivana Frasquet y Carmen G. Monerris (eds.), Cuando todo era posible. Liberalismo y antiliberalismo en España e Hispanoamérica (1780-1842), Sílex, Madrid, 2016, p. 238.

7 Alberto Gil Novales, Diccionario biográfico de España (1808-1833). De los orígenes del liberalismo a la reacción absolutista, Fundación Mapfre, Madrid, 2010, Tomo III, p. 2449.

8 Obra reseñada, p.113. 
del $15 \%$ en las de 1821 , pero en el conjunto de las Cortes del Estatuto Real, entre 1834 y 1836, los procuradores militares representaron el 21, $81 \%$ y en las constituyentes de 1836 el 14,8\%, no parece que el Trienio destaque especialmente en ese aspecto ${ }^{9}$. Todo ello no quita que sea acertada su apreciación sobre la elevada politización del ejército en ese periodo.

Por último, Ivana Frasquet escribe el necesario capitulo sobre la España americana, en el que explica el impacto de la revolución española en el conflicto colonial y cómo Fernando VII obstaculizó que pudieran prosperar las propuestas transaccionales, ya muy dificultadas por la propia Constitución y la falta de decisión de los diputados de la metrópoli. En su opinión: "El régimen liberal no supo llevar a cabo una política de reconocimiento que compensara la siempre amenazante estrategia militar del monarca y del Consejo de Estado. No se trataba de ceguera política, sino de incapacidad para reformar un diseño constitucional que atenazaba un modelo de estado alejado de la realidad" 10 .

El apartado sobre la vida política incluye estudios de Elisabel Larriba sobre la prensa, Álvaro París Martín sobre la Milicia Nacional, Jordi Roca Vernet sobre las Sociedades Patrióticas, Andoni Artola Renedo sobre la política religiosa y Ramón Arnabat Mata sobre la contrarrevolución y la antirrevolución. Si en el primero se resalta la importancia de la muy politizada prensa, que conoció una verdadera eclosión tras la recuperación de la libertad de imprenta, sobre el segundo se podría dudar si no estaría mejor situado en el apartado anterior, pero París Martín aclara ya en la primera línea que la milicia Nacional "constituye -junto a la prensa y las sociedades patrióticas- el espacio de participación y aprendizaje político más importante del Trienio". Tras una buena descripción de las características y funciones de la milicia, cierra su texto con un breve subcapitulo, que titula "violencia y politica", en el que, junto a consideraciones discutibles, realiza aseveraciones que, en mi opinión, solo pueden calificarse de excesivas o incluso de infundadas.

Dentro de lo discutible está la afirmación de que "El modelo de ciudadanía que defendian los exaltados era excluyente, porque dejaba fuera a los enemigos de la Constitución, señalados como facciosos y herejes politicos"11. Si se trata de los enemigos de la Constitución, no eran solo de los exaltados los que los consideraban enemigos y querían excluirlos, lo hacian prácticamente todos los liberales, con la excepción -no expresada, pero real- de los fronterizos afrancesados y quizá algún moderado a nivel personal y era así por lo que señala Ramón Arnabat en su capítulo de este mismo libro: "La mentalidad inquisitorial que

9 Quintí Casals Bergés, La representación parlamentaria en España durante el primer liberalismo (1810-1836), Edicions de la Universitat de Lleida-Servicio de Publicaciones de la Universidad de Cádiz, Lleida-Cádiz, 2014.

10 Obra reseñada, p. 183.

11 Obra reseñada, p. 233 
trazaba una división excluyente entre el bien y el mal formaba parte de la cultura politica de los sectores reaccionarios y contrarrevolucionarios y no ofrecía margen a la convivencia politica, al contrario, se articulaba alrededor de una política segregacionista y excluyente que pretendía eliminar o aplastar al otro. Esta política dejaba poco espacio vital y político a los perdedores, sobre todo cuando estos eran liberales (1814 o 1823). Incluso cuando los perdedores eran los contrarrevolucionarios su ideología excluyente no les permitía vivir en un país gobernado por los otros (1820 o 1840)"12. Poco cabe añadir ¿Qué posibilidad de diálogo existía con los que querian destruir el sistema politico y enviar a la cárcel o al patíbulo a los defensores de la Constitución? Los liberales del Trienio ya habian probado la medicina absolutista en 1814 , sufrian las tropelias y crimenes de las partidas ultras, a veces simples bandidos, sabian, desde 1821, lo que había pasado en Italia y conocian los complots e intentos de golpes de estado de los serviles ¿qué debían hacer para ser cívicos y no excluyentes?

Otra cosa es el sectarismo exaltado hacia los moderados y, especialmente, los afrancesados. Era mutuo, en cualquier caso, y corrobora algo que afirma el autor y es cierto: que se tardó en aceptar la pluralidad política dentro del liberalismo. A pesar de todo, estas desavenencias se movieron dentro de determinados límites, salvo algún incidente aislado, y los debates y las variables votaciones de las Cortes, la reconciliación de 1823 entre exaltados masones y moderados argüellistas o la escisión conciliadora de los comuneros de ese mismo año demuestran que los enfrentamientos entre las corrientes liberales tenían distinto carácter del que todas ellas mantuvieron con los enemigos del sistema.

Lo que no consigo encontrar en esos tres años de régimen constitucional es nada parecido al "Terror francés". En el periodo de la Convención, el "terror" estaba institucionalizado, en la España del Trienio no existieron tribunales revolucionarios ni leyes que amparasen una represión indiscriminada, ningún gobierno pretendió establecerlo. Es cierto que en algunos sitios y en determinadas situaciones hubo detenciones de realistas e incluso alguna deportación como consecuencia de motines populares, especialmente tras la invasión austriaca de Italia o ante la amenaza de alguna acción realista, pero siempre intervinieron las autoridades para restablecer el orden, destituir incluso a jefes políticos que se habian excedido, liberar a los detenidos irregularmente u ordenar el retorno de los desterrados, salvo que, en contadas ocasiones, encontrasen necesario el confinamiento, algo que, por ejemplo, practicó con frecuencia el nada jacobino general Narváez en la época isabelina y, como es bien sabido, sucedió también en otras etapas de la historia española contemporánea. Todas las corrientes liberales se distanciaron del terror jacobino y lo habitual es que condenasen con fuerza las manifestaciones en las que se gritaba “Tamajón, Tamajón!” o se exhibía el martillo amenazador. El Zurriago

12 Obra reseñada, pp. 287-288. 
no era una publicación oficial, todo lo contrario, las autoridades, incluso las "exaltadas", hicieron lo posible por cerrarlo y acabaron persiguiendo a sus editores.

Sostener que la de la Milicia Nacional "es una historia de violencia, terror político y guerra civil" no se corresponde con la realidad. Las actuaciones de la milicia fueron habitualmente pacificas y festivas, o policiales para perseguir a delincuentes, pero ajustadas a la ley. Solo cuando los levantamientos de los realistas, no de los milicianos, provocaron una situación de guerra civil tuvo que intervenir y solo en algunas regiones, sobre todo en Cataluña, cuando el conflicto armado se enquistó en 1822, o cuando se produjo la invasión francesa de 1823, cayó en actuaciones de violencia comparables a las de sus adversarios. En cualquier caso, lo que sucedió en el nordeste en 1822 y 1823 recuerda más a la primera guerra carlista que al terror jacobino ${ }^{13}$.

Es necesario estudiar la violencia liberal, que existió especialmente al final del Trienio, en un contexto de guerra civil -aunque fuese limitada- y de invasión extranjera, pero es necesaria la prudencia a la hora de establecer analogías que distorsionan lo que realmente sucedió.

Jordi Roca Vernet analiza las características de las sociedades patrióticas, un extraordinario fenómeno que se extendió con rapidez por toda España. Estas entidades contribuyeron a difundir la Constitución, los debates parlamentarios y la prensa y a la politización de la sociedad. Fueron también una vía de participación, de expresión de las opiniones y deseos de la ciudadanía, y una de las escasas oportunidades de actuación política de las mujeres, como bien señala el autor. Es un buen trabajo, al que solo le matizaría las consideraciones finales sobre la "justicia popular". Que un consejo de guerra se reuniese en 1823 en la sede de la Tertulia Patriótica de Lacy no lo convierte en un tribunal popular, ni los socios hicieron de jueces o jurados. Tampoco me parece muy acertado calificar de "justicia popular" la labor fiscalizadora de la actuación del gobierno o la denuncia de las infracciones de la Constitución, quizá sea más apropiado relacionarlas con la actividad que en el futuro realizarian los partidos políticos y otro tipo de asociaciones, al fin $\mathrm{y}$ al cabo, solía limitarse a debates públicos, elevación de escritos a las autoridades y, en todo caso, manifestaciones populares en la calle. Sobre los sucesos de 1821, condenados y revertidos por las Cortes y el gobierno, me remito a lo que comenté anteriormente.

Andoni Artola estudia la reforma eclesiástica que intentaron los liberales y la compleja relación de la iglesia con el nuevo sistema, cuyos principios rechazaba la mayoría de los eclesiásticos. Cierra el apartado Ramón Arnabat Mata con un capitulo sobre los que repudiaban el nuevo sistema constitucional. Es muy interesante su distinción entre "la contrarrevolución, entendida como el conjunto de estrategias

13 Jordi Roca Vernet, "La violencia politica del liberalismo exaltado durante el Trienio Liberal. La defensa del régimen constitucional desde Barcelona", Pasado y Memoria. Revista de Historia Contemporánea, n²2, pp. 155-186. 
políticas puestas en marcha por las viejas élites reaccionarias para acabar con la revolución y el liberalismo" y "La antirrevolución, entendida como el conjunto de respuestas de las clases populares agraviadas cultural y socialmente por la praxis revolucionaria y liberal"14. Profundiza, así, en las características del "realismo", que define como "la confluencia de la contrarrevolución y la antirrevolución bajo la hegemonía de la primera". Especialista en el tema, ofrece una notable aportación, rigurosa y documentada.

Abre el bloque de la sociedad un trabajo póstumo de Jean-Philippe Louis, excelente historiador, prematuramente fallecido en 2020, a quien con justicia se ha dedicado el libro. El hispanista francés realiza una aproximación a las élites del Trienio, en la que las presenta "como un mundo complejo en continuo dinamismo, inmerso en procesos a largo plazo, siendo el Trienio constitucional un momento de aceleración debido a que se dio un nivel muy alto de fracturas entre las élites, lo que constituye un elemento fundamental de la fuerza del cambio provocado por la revolución liberal y de la violencia que la acompaña"15. Aunque reconoce lo limitado de las fuentes en algunos casos, estudia tanto las élites sociales como las políticas y administrativas y concluye que "el Trienio liberal fue un periodo que favoreció un proceso a largo plazo de renovación de las élites", que se incrementaría tras la reacción de 1823.

Elena Fernández aborda la situación de las mujeres y su dificil incorporación a la vida pública. Francisco Javier Solans vuelve sobre el tema de la religión y destaca, entre otras cosas, el papel simbólico de la Inquisición, una suerte de Bastilla española, cuyos edificios fueron asaltados e inclusos incendiados en numerosas ciudades y los presos liberados. Marie-Angèle Orobon y Juan Francisco Fuentes estudian el papel de la calle, en esta revolución urbana que concedió un nuevo protagonismo al pueblo: lugar de fiesta y de combate, de protesta y de socialización.

Se inicia el apartado de la cultura con un trabajo de Jesús A. Martínez Martín titulado "Las palabras, las letras y la cultura política", en el que se acerca tanto a la cultura oral de los cafés, las sociedades y las tribunas o los teatros, como a la impresa de libros, periódicos y folletos. Es muy interesante lo que relata sobre las formas de lectura en una sociedad mayoritariamente analfabeta. Fernando Durán López estudia la literatura de la época, Marie Salgues el importantísimo papel del teatro y Juan José Carreras la música. Es un conjunto de temas no muy habitual en los libros de historia y un verdadero acierto que se haya incluido en esta obra

El libro se cierra con cuatro capítulos referidos, el primero, al escenario internacional, a cargo de Rosario de la Torre; a la Constitución gaditana en Italia, escrito por Silvia Sonetti; a la invasión

\footnotetext{
14 Obra reseñada, p. 285.

15 Obra reseñada, pp. 312-313.
} 
francesa de 1823, por Gonzalo Butrón Prida, y al exilio, redactado por Juan Luis Simal. Todos son conocidos especialistas en los temas que tratan, indispensables en una publicación sobre la revolución española que abrió la primera gran crisis del sistema de la Restauración a solo cinco años del final de Congreso de Viena, que sufrió la segunda intervención inspirada por la Santa Alianza y cuya derrota provocó el tercer gran exilio de la España contemporánea, tras el de los afrancesados de 1813 y el liberal de 1814 .

Se trata, por tanto, de una obra que ya puede considerarse imprescindible, en la que se abordan con rigor y desde diversos enfoques aspectos fundamentales del Trienio Liberal. Es obligado felicitar a los coordinadores y a todos los autores, independientemente de las discrepancias concretas que he expresado en algún caso y que son no solo inevitables cuando dos historiadores analizan un acontecimiento o periodo del pasado, sino saludables para la ciencia. Desde el punto de vista editorial, solo se le puede reprochar la falta de un índice de nombres, que hubiera sido útil en un libro tan extenso y denso como este.

Enviado el (Submission Date): 06/05/2021

Aceptado el (Acceptance Date): 8/05/2021 